\title{
Study of Photodegradation Performance and Ability of Lead Removal of Synthesized Maghemite Nanoparticles Using Ziziphus Jujuba Extract
}

\section{Abdolhossein Miri}

Zabol University of Medical Sciences

\section{Atefeh Sadat Sedighi}

Zabol University of Medical Sciences

Ahmad Najafidoust

Sahand University of Technology

Mehrdad Khatami

Bam University of Medical Sciences

Mina sarani ( $\triangle$ minasarani64@gmail.com )

Zabol University of Medical Sciences https://orcid.org/0000-0002-0681-0421

\section{Research Article}

Keywords: -Fe203 NPs, Ziziphus jujuba, Lead removal, Photocatalytic Activity, Green chemistry

Posted Date: May 27th, 2021

DOI: https://doi.org/10.21203/rs.3.rs-545585/v1

License: (9) This work is licensed under a Creative Commons Attribution 4.0 International License.

Read Full License 


\section{Abstract}

Today, Water pollutants such as heavy metals and dyes are very important dangers to the nature. Metals such as lead, chromium, mercury and arsenic are examples of heavy metals which are toxic to living things, even sometime at the lowest concentrations. For resolve this challenge, Magnetic nanoparticles are attractive compound because of their advantages such as high efficiency, fast recovery capability, high surface area, easy transportation and inexpensive. We presented an easy and eco-friendly route for the synthesis of iron oxide nanoparticles using Ziziphus jujuba extract. In order to determine the physical, chemical and optical properties of the synthesized samples, Fourier-transform infrared (FT-IR), powder Xray diffraction (PXRD), vibrating sample magnetometer (VSM), field emission scanning electron microscope (FESEM), energy dispersive X-ray (EDX), transmission electron microscopy (TEM), and Raman analyses were deployed. PXRD results showed that the synthesized nanoparticles have maghemite form of $\left(\mathrm{y}-\mathrm{Fe}_{2} \mathrm{O}_{3}\right)$. FESEM and TEM results demonstrated that the size of these nanoparticles was in range of 20-50 nm, and had spherical shapes. Raman spectrum confirmed the cubic structure of $\mathrm{Y}^{-}$ $\mathrm{Fe}_{2} \mathrm{O}_{3}$ NPs. Survey of magnetic properties showed that the synthesized maghemite nanoparticles ( $\mathrm{Y}-$ $\mathrm{Fe}_{2} \mathrm{O}_{3}$ NPs) were superparamagnetic. The ability to remove lead from aqueous solution was investigated using these nanoparticles. The results showed that the synthesized nanoparticles were capable of removing $96 \%$ of lead at $\mathrm{pH}=7$ and $1 \mathrm{mg} / \mathrm{L}$ loading of nanoparticles. The photocatalytic activity of $\mathrm{Y}-$ $\mathrm{Fe}_{2} \mathrm{O}_{3} \mathrm{NPs}$ was studied on methylene blue (MB) dye; as a result, $\mathrm{MB}$ at $\mathrm{pH}=7$ and $1 \mathrm{gr}$ dosage of $\mathrm{\gamma}-\mathrm{Fe}_{2} \mathrm{O}_{3}$ had the highest removal percentage (92.8\%) during 160 minute using $\mathrm{Y}-\mathrm{Fe}_{2} \mathrm{O}_{3}$ which calcined at $400{ }^{\circ} \mathrm{C}$. The reusability results showed that after four cycles of using the $\mathrm{y}-\mathrm{Fe}_{2} \mathrm{O}_{3}-400$, the obtained degradation of methylene blue was about $87.1 \%$. Thus, synthesized $y-\mathrm{Fe}_{2} \mathrm{O}_{3} \mathrm{NPs}$ can be a good alternative for removing heavy metals and industrial dyes from contaminated waters.

\section{Introduction}

Generally, iron oxide is a chemical compound containing iron and oxygen, and is widely available in nature and has attracted much attention due to its various oxidation states [1]. Iron oxide can be utilized in industries as catalysts, pigments, sensors; heavy metal contaminates removal agents, and bacteriakilling materials. It was also explored in clinical trials as a targeted drug delivery system for cancer therapy [2,4-7]. Due to the ability and widespread applications of iron oxide nanoparticles, much attention has been paid to the synthesis of well-organized nanoparticles with unique sizes and morphologies. Indeed, by decreasing the size of particles, their surface activities were also increased. Chemical and physical synthesis methods such as co-precipitation [8], hydrothermal [9], solvothermal [10,11] and microemulsion [12] were deployed for the preparation of iron oxide nanoparticles; but today due to the low toxicity, cheapness, availability, high efficiency and environmentally friendly properties, natural metabolites and resources have been utilized to synthesize these nanoparticles with unique features [35,13-15]. 
Water pollutants such as heavy metals and dyes are very important dangers to the nature. Metals such as lead, chromium, mercury and arsenic are examples of heavy metals which are toxic to living things, even sometime at the lowest concentrations [16]. The risk of contamination of water by paint compounds threatens aquatic life; additionally, it can raise the risk of cancer in humans. Due to the environmental hazards and toxic health effects of heavy metals and dyes, various technologies such as chemical precipitation, ion exchange, and adsorption have been developed to remove them $[17,18]$. Magnetic nanoparticles are attractive compound because of their advantages such as high efficiency, fast recovery capability, high surface area, easy transportation and inexpensive [19]. Sun et a/ have synthesized $\mathrm{Fe}_{3} \mathrm{O}_{4} @ \mathrm{SiO}_{2}-\mathrm{NH}_{2}$ nanoparticles and evaluated their capabilities for removing green malachite dye. Their results showed high efficiency for the elimination of green malachite using the modified magnetite [20].

Ziziphus jujuba (from the family of Rhamnaceae) grows in tropical regions, parts of India and Myanmar. Its fruit contains many compounds including saponins, alkaloids, flavonoids, terpenoids, glycosides, ascorbic acid, thiamine, riboflavin-bioflavonoids and pectin. Due to the invaluable ingredients of $Z$. jujube, it can be expected that its extract is able to reduce and stabilize iron salts [21]. Therefore, in this study, iron oxide nanoparticles ( $\mathrm{y}-\mathrm{Fe}_{2} \mathrm{O}_{3} \mathrm{NPs}$ ) were synthesized using aqueous extract of $Z$. jujuba fruit, and their efficacy as adsorbents for removing lead from aqueous solutions as well as their photocatalytic activity are investigated.

\section{Experiments}

\section{Extraction of Z. jujuba}

Dried Z. jujuba fruit was bought from Birjand. Then, kernels were separated from the fruit, and reside was powder. $20 \mathrm{~mL}$ of distilled water was added to $2 \mathrm{gr}$ of $Z$. jujube power. The mixture was shacked for 24 hours at $150 \mathrm{rpm}$, and the result was filtered using filter paper of Whatman ${ }^{\circledR}$ No.1; the filtrate was utilized for additional experimental procedures.

\section{Synthesis of $\mathrm{y}-\mathrm{Fe}_{2} \mathrm{O}_{3} \mathrm{NPs}$}

To synthesize nanoparticles, $90 \mathrm{~mL}$ of distilled water was poured to the $10 \mathrm{~mL}$ of $Z$. jujube extract. The solution was gradually added to $100 \mathrm{~mL}$ of iron (III) chloride $(0.1 \mathrm{M})$ solution. The final solution was stirred in a water bath at $70^{\circ} \mathrm{C}$ (about 3 hours). The $\mathrm{pH}$ of reaction was tuned 11 using sodium hydroxide $(1 \mathrm{M})$ solutions. Result was dark brown solution that dried in the oven at $90^{\circ} \mathrm{C}$. The resulting powder was calcined separately at 300,400 , and $500^{\circ} \mathrm{C}$ for about 2 hours, using furnace; the obtained iron oxide nanoparticles were brown in color and the schematic diagram is depicted in Fig. 1.

\section{Lead removal evaluations}

Aqueous solution of lead nitrate (II) was prepared with serials dilutions of $500,250,125,62.5,31.25$ and $15.625 \mathrm{mg} / \mathrm{L}$, and its adsorption was evaluated using atomic adsorption. The $\mathrm{pH}$ of 4, 6 and 8 was applied for each dilutions using $\mathrm{NaOH}(1 \mathrm{M})$ and $\mathrm{HCl}(1 \mathrm{M})$ solutions. $10 \mathrm{mg}$ of iron oxide nanoparticles 
was added to each dilution and well mixed using shaker at $150 \mathrm{rpm}$ for $60 \mathrm{~min}$; finally, the mixture was filtered and the filature adsorption was read using atomic adsorption device.

\section{Photocatalytic performance of $\mathrm{y}-\mathrm{Fe}_{2} \mathrm{O}_{3} \mathrm{NPs}$}

Semi-batch reactor was utilized to evaluate the photocatalytic activity of nanoparticles. In this study, samples were dispersed in heterogeneous form in organic pollutant of methylene blue. The reactor with the photocatalyst was placed in the dark on stirrer for 60 minutes to equilibrium the adsorptiondesorption. Additionally, a halogen lamp with a wavelength of visible light was employed as a radiation source. After adsorption-desorption equilibrium, the lamp was turned on, and the solution was exposed to visible light. Samples were taken at $20 \mathrm{~min}$ intervals and were centrifuged; and the absorption was read using a UV-Vis spectrophotometer (DR6000) at $665 \mathrm{~nm}$. Degradation efficiency was calculated using the Eq. 1.

\section{Degradation effiency $\%=\left(1-C / C_{0}\right) \times 100 \% \quad$ Eq. 1}

Which $\mathrm{C}_{0}$ is the initial concentration of the organic dye in water, and $\mathrm{C}$ is final concentration of dye in the solution in specified times after irradiation.

\section{Characterization}

Structure, morphology and size of the synthesized $\mathrm{y}-\mathrm{Fe}_{2} \mathrm{O}_{3} \mathrm{NPs}$ were identified through Raman (Takram P50C0R10 model in $532 \mathrm{~nm}$ leaser wave length), Powder X-ray diffraction (PXRD, X'Pert PRO MPD PANalytical model, Netherlands), Fourier transform infrared spectroscopy (FT-IR, Bruker Tensor27) and field energy scanning electron microscopy (FESEM, TESCAN model of MIRA3) methods.

\section{Results And Discussion}

Among the nanoparticles with commercial applications, iron oxide nanoparticles have unique properties with abundant applications. Thus, in this study, maghemite nanoparticles $\left(\mathrm{\gamma}-\mathrm{Fe}_{2} \mathrm{O}_{3} \mathrm{NPs}\right)$ were synthesized using aqueous solution of $Z$. jujube through simple and fast route with high efficiency.

\section{PXRD analysis}

PXRD is one of the efficient devices for materials analysis. The nature and size of particles were characterized using PXRD technique and the resulted patterns [9]. PXRD spectra of the $\mathrm{\gamma}-\mathrm{Fe}_{2} \mathrm{O}_{3} \mathrm{NPs}$ at 300,400 , and $500{ }^{\circ} \mathrm{C}$ are demonstrated in Fig. 2. In PXRD spectra, sharp peaks indicated the stability of nanoparticles. The high intensity of the peaks indicated strong scattering centers of X-ray in the crystalline phase. Generally, broadening of peaks in PXRD patterns of solid material can be attributed to particle size; wider PXRD peak indicated smaller particle sizes. Additionally, the sharpness of peaks implied the crystallinity of synthesized samples. According to the results obtained from PXRD, Miller 
indices of (220), (311), (400), (422), (511), (440) and (533) implied that synthesized samples are maghemite nanoparticles ( $\left.\mathrm{\gamma}-\mathrm{Fe}_{2} \mathrm{O}_{3} \mathrm{NPs}\right)$ with cubic structure (JCPDS: 39-1346) [22]. The crystallite size of these nanoparticles was calculated using the Debye-Scherrer equation (Equation 2).

$D=k \lambda / \beta \cos \theta$ Eq. 2

Where, $D$ is particle size on nanometer, $k$ is a fixed factor that is usually $k=1, \lambda$ is wavelength of $X$-ray (3.54 $\AA$ ), $\theta$ is radiation angle of $X$-ray (in degrees), and $\beta$ is peak width in half height of the peak that be expressed in units of length [23]. The crystallite size of synthesized $\mathrm{y}-\mathrm{Fe}_{2} \mathrm{O}_{3}$ nanoparticles at 300,400 , and $500{ }^{\circ} \mathrm{C}$ were estimated at $28.39,36.81$, and $45.72 \mathrm{~nm}$, respectively.

\section{FESEM and TEM analysis}

Analysis of FE-SEM for synthesized $\mathrm{y}-\mathrm{Fe}_{2} \mathrm{O}_{3}$ nanoparticles exhibited the round-shaped morphology of nanoparticles. The size ranges for synthesized $\mathrm{y}-\mathrm{Fe}_{2} \mathrm{O}_{3} \mathrm{NPs}$ at $300,400,500{ }^{\circ} \mathrm{C}$ were $20-25, \sim 35$, and $\sim 45$ $\mathrm{nm}$, respectively (Fig. 3), which were well-surrounded by the respective green coating. The images confirmed that these natural product-based nanoparticles had spherical shapes. The TEM image of synthesized $y-\mathrm{Fe}_{2} \mathrm{O}_{3} \mathrm{NPs}$ at $400{ }^{\circ} \mathrm{C}$ showed in Fig. 3 , which this figure has been depicted the particles about 40-50 nm sizes with spherical and almost uniform shapes.

\section{FT-IR analysis}

The FT-IR spectra of synthesized $\mathrm{y}-\mathrm{Fe}_{2} \mathrm{O}_{3}$ NPs at 300,400 , and $500{ }^{\circ} \mathrm{C}$ are shown in Fig. 4. In the FT-IR spectra, the absorption band in range $3414 \mathrm{~cm}^{-1}$ caused strong stretching vibration by created hydrogen bonding with $\mathrm{OH}$ groups, which absorbed by sample from medium. The absorption band in the range of $1624 \mathrm{~cm}^{-1}$ belongs to the adsorbed $\mathrm{H}_{2} \mathrm{O}$ groups on the nanoparticle surface. The presence of these peaks indicated that iron oxide nanoparticles are capable of absorbing large amounts of $\mathrm{OH}$ groups of $\mathrm{H}_{2} \mathrm{O}$ on their outer surfaces. The absorption band in the range of $619-500 \mathrm{~cm}^{-1}$ corresponds to the vibration bands $\mathrm{O}-\mathrm{Fe}-\mathrm{O}$ and $\mathrm{Fe}-\mathrm{O}[22,24]$.

\section{Raman analysis}

The Raman spectrum of the synthesized maghemite nanoparticles using aqueous extract of $Z$. jujube at $400{ }^{\circ} \mathrm{C}$ are shown in Fig. 5. The Raman modes of cubic spinal structures had five active modes including $A_{1}+E+3 T_{1}$. In the region of 286,687 and $716 \mathrm{~cm}^{-1}$, which are according to $A_{1}, E$ and $T_{1}$ modes, respectively. Raman spectrum confirmed the cubic structure of $\mathrm{y}-\mathrm{Fe}_{2} \mathrm{O}_{3} \mathrm{NPs}$ [25].

\section{VSM analysis}

The magnetic properties of the synthesized maghemite nanoparticles at $400{ }^{\circ} \mathrm{C}$ were investigated using the VSM technique (Fig. 6). Iron nanoparticles had no hysteresis ring and were superparamagnetic at room temperature. The saturation magnetization (Ms) at $400{ }^{\circ} \mathrm{C}$ was $65 \mathrm{emu} / \mathrm{g}$, which was less than the 
magnetic state of its bulk $\left(M_{s}=76 \mathrm{emu} / \mathrm{g}\right)$ [26]. This decrease in saturation might be due to the effect of the reduced particle size.

\section{The survey of ability of lead removes}

Studies demonstrated that iron oxide nanoparticles were able to remove contaminants. Thus, in this study, the ability of nanoparticles to remove lead was investigated. To evaluate the effect of $\mathrm{pH}$ on nanoparticle synthesis, three pHs including 4, 6, and 8 were considered. Based on the results, the pH optimum exhibited that alkaline ambiance was the best condition for the removal of lead. Considering that, the surface charge of $\mathrm{Y}-\mathrm{Fe}_{2} \mathrm{O}_{3} \mathrm{NPs}$ can play the most important role in this phenomenon; alkaline ambiance improves the surface charge of nanoparticles [7]. Therefore, the adsorption of lead ions in alkaline ambiance was more than in neutral and acidic ambiance.

In this test, other variables such as contact time and concentration of the synthesized $y-\mathrm{Fe}_{2} \mathrm{O}_{3} \mathrm{NPs}$ (at $400{ }^{\circ} \mathrm{C}$ ) were considered constantly, and the ability of nanoparticles to remove lead was investigated at 7.90 to $500 \mathrm{mg} / \mathrm{L}$ concentrations of pollutants. Lead solution without nanoparticles was considered as a control. The adsorption efficiency was calculated using equation 3.

$R=\left(C_{i}-C_{e} / C_{i}\right) \times 100$ Eq. 3

Where, $C_{i}$ is the initial concentration of lead in solution $(\mathrm{mg} / \mathrm{L}), \mathrm{C}_{\mathrm{e}}$ is equilibrium concentration of lead in solution after adsorption process $(\mathrm{mg} / \mathrm{L})$, and $\mathrm{R}$ is absorption efficiency. Residual concentrations of lead in solution after adsorption process were calculated by the obtained line equation in Fig. 7A; and by using the obtained results, the adsorption efficiency of lead via the synthesized $y-\mathrm{Fe}_{2} \mathrm{O}_{3}$ nanoparticles at $400{ }^{\circ} \mathrm{C}$ was calculated (Fig. 7B).

Fig. 7B shows that by decreasing the concentrations of lead in the reaction ambiance, the lead removal by nanoparticles was successfully completed. The ratio of 1:1 between the concentration of nanoparticles and lead showed the highest absorption efficiency. As a result, $\mathrm{\gamma}-\mathrm{Fe}_{2} \mathrm{O}_{3} \mathrm{NPs}$ were able to remove lead.

\section{Photocatalytic activity evaluations}

\section{Methylene blue degradation}

Fig. $8 \mathrm{~A}$ shows the adsorption diagram of methylene blue dye by the synthetized nanoparticles at 300 , 400 , and $500{ }^{\circ} \mathrm{C}$ calcination temperatures. In order to investigate the photocatalytic activity of obtained samples, the applied test condition included $\mathrm{pH}=7,1 \mathrm{~g} / \mathrm{L}$ of catalyst and $20 \mathrm{mg} / \mathrm{L}$ of initial dye concentration. The adsorption of organic dyes using photocatalysts method is directly related to the specific surface area of the photocatalysts. In Fig. 8A, the absorption rate of $\mathrm{y}-\mathrm{Fe}_{2} \mathrm{O}_{3} \mathrm{NPs}$ at 300,400 , and $500{ }^{\circ} \mathrm{C}$ were $18.2,20.3$, and $16.3 \%$, respectively, which demonstrated that the adsorption rate synthesized sample at $400{ }^{\circ} \mathrm{C}$ was higher than other samples. Fig. 8B demonstrates that the degradation rate for $\mathrm{Y}^{-}$ 
$\mathrm{Fe}_{2} \mathrm{O}_{3} \mathrm{NPs}$ at 300,400 , and $500{ }^{\circ} \mathrm{C}$ were $84.8 \%, 92.8 \%$, and $70.2 \%$, respectively. According to XRD and FESEM results, by increasing the calcination temperature from $300{ }^{\circ} \mathrm{C}$ to $500{ }^{\circ} \mathrm{C}$, the crystal size was also increased. In photocatalytic activity, ratio of surface-to-volume have role importance than to crystallite size of particles. So, the ratio of surface-to-volume of synthesized nanoparticles at $400{ }^{\circ} \mathrm{C}$ is higher than to samples of $300{ }^{\circ} \mathrm{C}[27,28]$, in results, the synthesized nanoparticles at $400{ }^{\circ} \mathrm{C}$ were exhibited better photocatalytic performances. In sample of $500{ }^{\circ} \mathrm{C}$, degradation activity was reduced due to saturation of active sites.

\section{Influence of $\mathrm{pH}$}

$\mathrm{pH}$ is one of the most effective operational parameters in the photocatalytic process. Given that $\mathrm{pH}$ of solution changes the surface charge of nanocatalyst, it has a great influence between the dye molecules and electric charge of photocatalytic. Thus, finding the right amount of $\mathrm{pH}$ parameter is essential to increase the removal efficiency [29]. In order to find the optimal $\mathrm{pH}$, the photocatalytic analyses were performed in three different values of 3,7 and 11. Fig. 9 demonstrates that the removal efficiency of MB dye at $\mathrm{pH}$ ranges of 3,7 and 10 were about $44.9 \%, 89.1 \%$ and $95.8 \%$, respectively. The results exhibited that $\mathrm{y}-\mathrm{Fe}_{2} \mathrm{O}_{3} \mathrm{NPs}$ (at $400{ }^{\circ} \mathrm{C}$ ) had good photocatalytic activity at basic and natural media.

\section{Reusability study}

Reusability of photocatalytic is a very important and decisive factor for practical applications. To investigate the stability of synthesized $\mathrm{\gamma}-\mathrm{Fe}_{2} \mathrm{O}_{3} \mathrm{NPs}$ at $400{ }^{\circ} \mathrm{C}$, they were exposed to solar light at initial concentrations of $20 \mathrm{mg} / \mathrm{L}$ of methylene blue, $1 \mathrm{~g} / \mathrm{L}$ of catalyst loading and $\mathrm{pH}=7$ for 160 minutes. After each photocatalytic test, $\mathrm{\gamma}-\mathrm{Fe}_{2} \mathrm{O}_{3} \mathrm{NPs}$ was separated, washed and dried in an oven at $110{ }^{\circ} \mathrm{C}$ for about 2 hours. The results showed that after four cycles of using the $\mathrm{y}-\mathrm{Fe}_{2} \mathrm{O}_{3}-300$, the obtained degradation of methylene blue was about $87.1 \%$ (Fig. 10). It appears that $\mathrm{y}-\mathrm{Fe}_{2} \mathrm{O}_{3} \mathrm{NPs}$ can be considered as reusable, functional and active of nanophotocatalysts in environmental applications.

\section{Conclusions}

In this study, maghemite nanoparticles $\left(\mathrm{\gamma}-\mathrm{Fe}_{2} \mathrm{O}_{3} \mathrm{NPs}\right)$ were green-synthesized at 300,400 , and $500{ }^{\circ} \mathrm{C}$ calcination temperatures using aqueous extract of $Z$. jujuba fruit. The synthesized nanoparticles had a particle size in range of about 20-50 nm. According to the PXRD and FESEM analyses, the calcined sample at $300{ }^{\circ} \mathrm{C}$ had the lowest particle and crystal size. By increasing calcination temperature, the particle size was also increased. The ability of the green-fabricated nanoparticles to remove lead from the aqueous medium was studied. The removal efficiency of $\mathrm{Y}^{-} \mathrm{Fe}_{2} \mathrm{O}_{3} \mathrm{NPs}$ indicated the excellent ability of them to remove lead. Additionally, the study of photocatalytic activity of these nanoparticles at $400{ }^{\circ} \mathrm{C}$ demonstrated their promising potentials in degradation/removal of MB dye. It can be noted that the number of active sites at the surface of catalysts is high and leads to the increased photocatalytic 
activity. Thus, the synthesized $\mathrm{y}-\mathrm{Fe}_{2} \mathrm{O}_{3} \mathrm{NPs}$ can be a good alternative for removing heavy metals and industrial dyes from the contaminated waters.

\section{Declarations}

\section{Disclosure statement}

The authors declare that they have no competing interests.

\section{References}

1. Khan I, Saeed K, Khan I (2019) Nanoparticles: Properties, applications and toxicities. Arab J Chem 12:908-931

2. Ali A, Hira Zafar MZ, ul Haq I, Phull AR, Ali JS, Hussain A (2016) Synthesis, characterization, applications, and challenges of iron oxide nanoparticles. Sci Appl 9:49

3. Miri A, Najafzadeh H, Darroudi M, Miri MJ, Kouhbanani MAJ, Sarani M (2021) Iron Oxide Nanoparticles: Biosynthesis, Magnetic Behavior, Cytotoxic Effect. ChemistryOpen 10:327

4. Khatami M, Alijani HQ, Haghighat M, Bamrovat M, Azhdari S, Ahmadian M, Nobre M, Heidari M, Sarani M, Khatami S (2019) Green Synthesis of Amorphous Iron Oxide Nanoparticles and their Antimicrobial Activity against Klebsiella pneumonia, Pseudomonas aeruginosa and Escherichia coli. Iran J Biotechnol 10:33-39

5. Miri A, Khatami M, Sarani M (2020) Biosynthesis, magnetic and cytotoxic studies of hematite nanoparticles. J Inorg Organomet Polym Mater 30:767-774

6. Lombardo D, Kiselev MA, Caccamo MT (2019) Smart nanoparticles for drug delivery application: development of versatile nanocarrier platforms in biotechnology and nanomedicine. J Nanomater 2019

7. Popescu RC, Savu D, Dorobantu I, Vasile BS, Hosser H, Boldeiu A, Temelie M, Straticiuc M, lancu DA, Andronescu E, Wenz F, Giordano FA, Herskind C, Veldwijk MR (2020) Efficient uptake and retention of iron oxide-based nanoparticles in HeLa cells leads to an effective intracellular delivery of doxorubicin. Sci Rep 10:10530

8. Besenhard MO, LaGrow AP, Hodzic A, Kriechbaum M, Panariello L, Bais G, Loizou K, Damilos S, Cruz MM, Thanh NTK (2020) Co-precipitation synthesis of stable iron oxide nanoparticles with $\mathrm{NaOH}$ : New insights and continuous production via flow chemistry. J Phys Chem C 399:125740

9. Ge S, Shi X, Sun K, Li C, Uher C, Baker JR Jr, Banaszak Holl MM, Orr BG (2009) Facile hydrothermal synthesis of iron oxide nanoparticles with tunable magnetic properties. J Phys Chem C 113:1359313599

10. Li S, Zhang T, Tang R, Qiu H, Wang C, Zhou Z (2015) Solvothermal synthesis and characterization of monodisperse superparamagnetic iron oxide nanoparticles. J Magn Magn Mater 379:226-231 
11. Chen Y, Zhang J, Wang Z, Zhou Z (2019) Solvothermal synthesis of size-controlled monodispersed superparamagnetic iron oxide nanoparticles. Appl Sci 9:5157

12. Chin $A B$, Yaacob II (2007) Synthesis and characterization of magnetic iron oxide nanoparticles via w/o microemulsion and Massart's procedure. J Mater Proc Technol 191:235-237

13. Azhdari S, Sarabi RE, Rezaeizade N, Mosazade F, Heidari M, Borhani F, Abdollahpour-Alitappeh M, Khatami M (2020) Metallic SPIONP/AgNP synthesis using a novel natural source and their antifungal activities. Rsc Adv 10:29737-29744

14. Hooshmand S, Hayat SMG, Ghorbani A, Khatami M, Pakravanan K, Darroudi M (2020) Preparation and Applications of Superparamagnetic Iron Oxide Nanoparticles in Novel Drug Delivery Systems: An Overview Article. Curr Med Chem

15. Hamidian K, Najafidoust A, Miri A, Sarani M (2021) Photocatalytic performance on degradation of Acid Orange 7 dye using biosynthesized un-doped and $\mathrm{Co}_{\text {doped }} \mathrm{CeO}_{2}$ nanoparticles. Mater Res Bull 138:111206

16. Jaishankar M, Tseten T, Anbalagan N, Mathew BB, Beeregowda KN (2014) Toxicity, mechanism and health effects of some heavy metals. Interdiscip Toxicol 7:60

17. Tchounwou PB, Yedjou CG, Patlolla AK, Sutton DJ (2012) Heavy metal toxicity and the environment. Mol Clinic Environ Toxic 101:133-164

18. Sall ML, Diaw AKD, Gningue-Sall D, Aaron SE, Aaron JJ (2020) Toxic heavy metals: impact on the environment and human health, and treatment with conducting organic polymers, a review. Environ Sci Pollut Res 27:29927-29942

19. Lu H, Wang J, Stoller M, Wang T, Bao Y, Hao H (2016) An overview of nanomaterials for water and wastewater treatment. Adv Mater Sci Eng 2016

20. Sun L, Hu S, Sun H, Guo H, Zhu H, Liu M, Sun H (2015) Malachite green adsorption onto $\mathrm{Fe}_{3} \mathrm{O}_{4} @$ $\mathrm{SiO}_{2}-\mathrm{NH}_{2}$ : isotherms, kinetic and process optimization. RSC Adv 5:11837-11844

21. Mahajan R, Chopda M (2009) Phyto-Pharmacology of Ziziphus jujuba Mill-A plant review. Pharmacogn Rev 3:320

22. Nazari M, Ghasemi N, Maddah H, Mousavi Motlagh M (2014) Synthesis and characterization of maghemite nanopowders by chemical precipitation method. J Nanostruct Chem 4:99

23. Miri A, Sarani M, Khatami M (2020) Nickel-doped cerium oxide nanoparticles: biosynthesis, cytotoxicity and UV protection studies. Rsc Adv 10:3967-3977

24. Malakotian M, Asadzadeh SN, Khatami M, Ahmadian M, Heidari MR, Karimi P, Firouzeh N. Varma RS (2019) ) Protocol encompassing ultrasound $/ \mathrm{Fe}_{3} \mathrm{O}_{4}$ nanoparticles/persulfate for the removal of tetracycline antibiotics from aqueous environments. Clean Technol Environ Policy 21:1665-1674

25. El Mendili Y, Bardeau J-F, Randrianantoandro N, Greneche JM, Grasset F (2016) Structural behavior of laser-irradiated $\gamma-\mathrm{Fe}_{2} \mathrm{O}_{3}$ nanocrystals dispersed in porous silica matrix: $\gamma-\mathrm{Fe}_{2} \mathrm{O}_{3}$ to $a-\mathrm{Fe}_{2} \mathrm{O}_{3}$ phase transition and formation of $\varepsilon-\mathrm{Fe}_{2} \mathrm{O}_{3}$. Sci Technol Adv Mater 17:597-609 
26. Cao D, Li H, Pan L, Li J, Wang X, Jing P, Cheng X, Wang W, Wang J, Liu Q (2016) High saturation magnetization of $\mathrm{y}-\mathrm{Fe}_{2} \mathrm{O}_{3}$ nano-particles by a facile one-step synthesis approach. Sci Rep 6:1-9

27. Kim DS, Kwak S-Y (2007) The hydrothermal synthesis of mesoporous $\mathrm{TiO}_{2}$ with high crystallinity, thermal stability, large surface area, and enhanced photocatalytic activity. Appl Catal A Gen 323:110-118

28. Takari A, Ghasemi AR, Hamadanian M, Sarafrazi M, Najafidoust A (2021) Molecular dynamics simulation and thermo-mechanical characterization for optimization of three-phase epoxy/ $/ \mathrm{TiO}_{2} / \mathrm{SiO}_{2}$ nano-composites. Polym Test 93:106890

29. Najafidoust A, Hakki HK, Avalzali HA, Karimi Ashraf Bonab M (2019) The role of Diethanolamine as stabilizer in controlling morphology, roughness and photocatalytic activity of $\mathrm{ZnO}$ coatings in sonophotodegradation of methylene blue. Mater Res Exp 6:096401

\section{Figures}

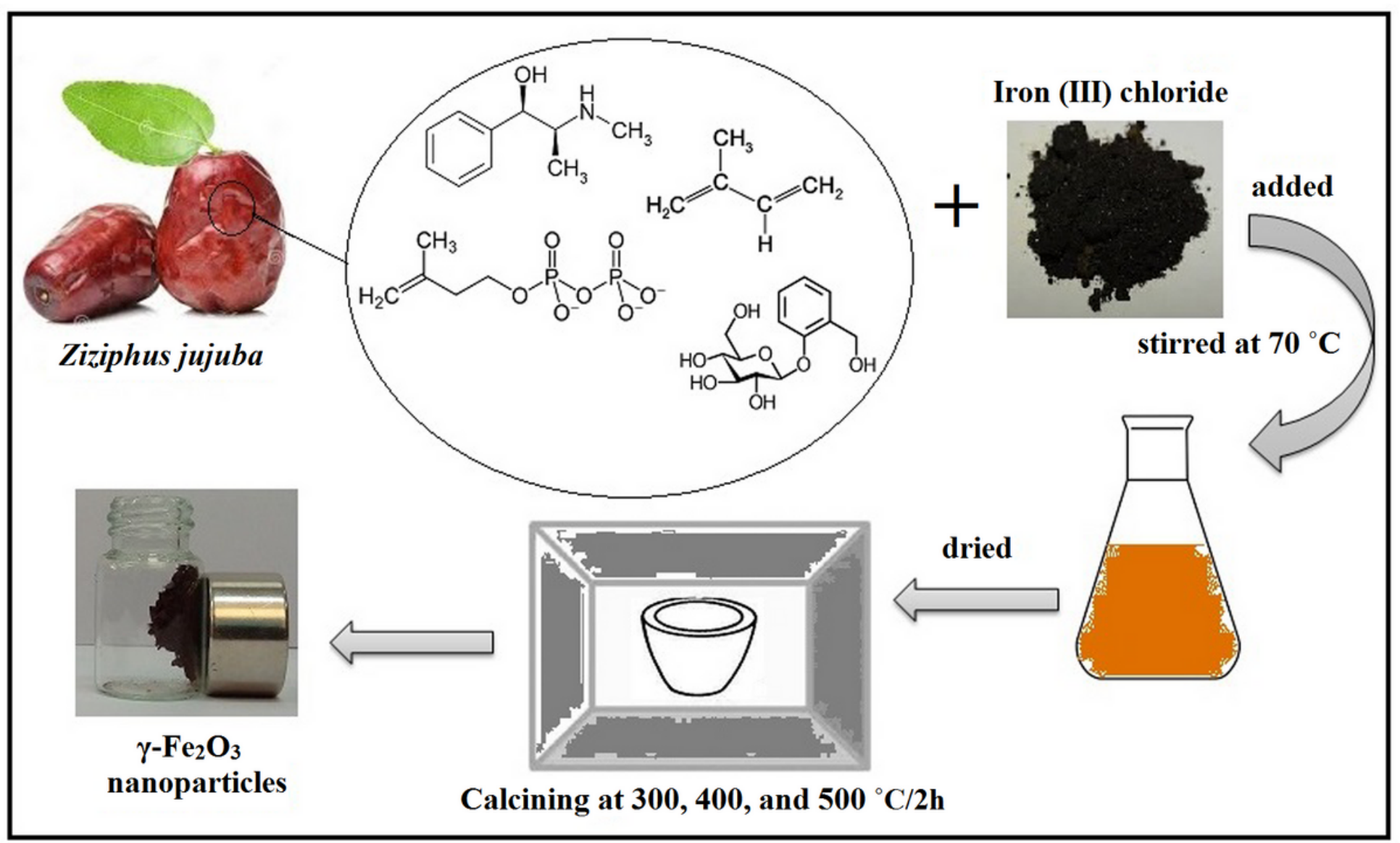

Figure 1

Schematic diagrams of the synthesis of $y$-Fe203 NPs using extract of Z. jujuba fruit. 


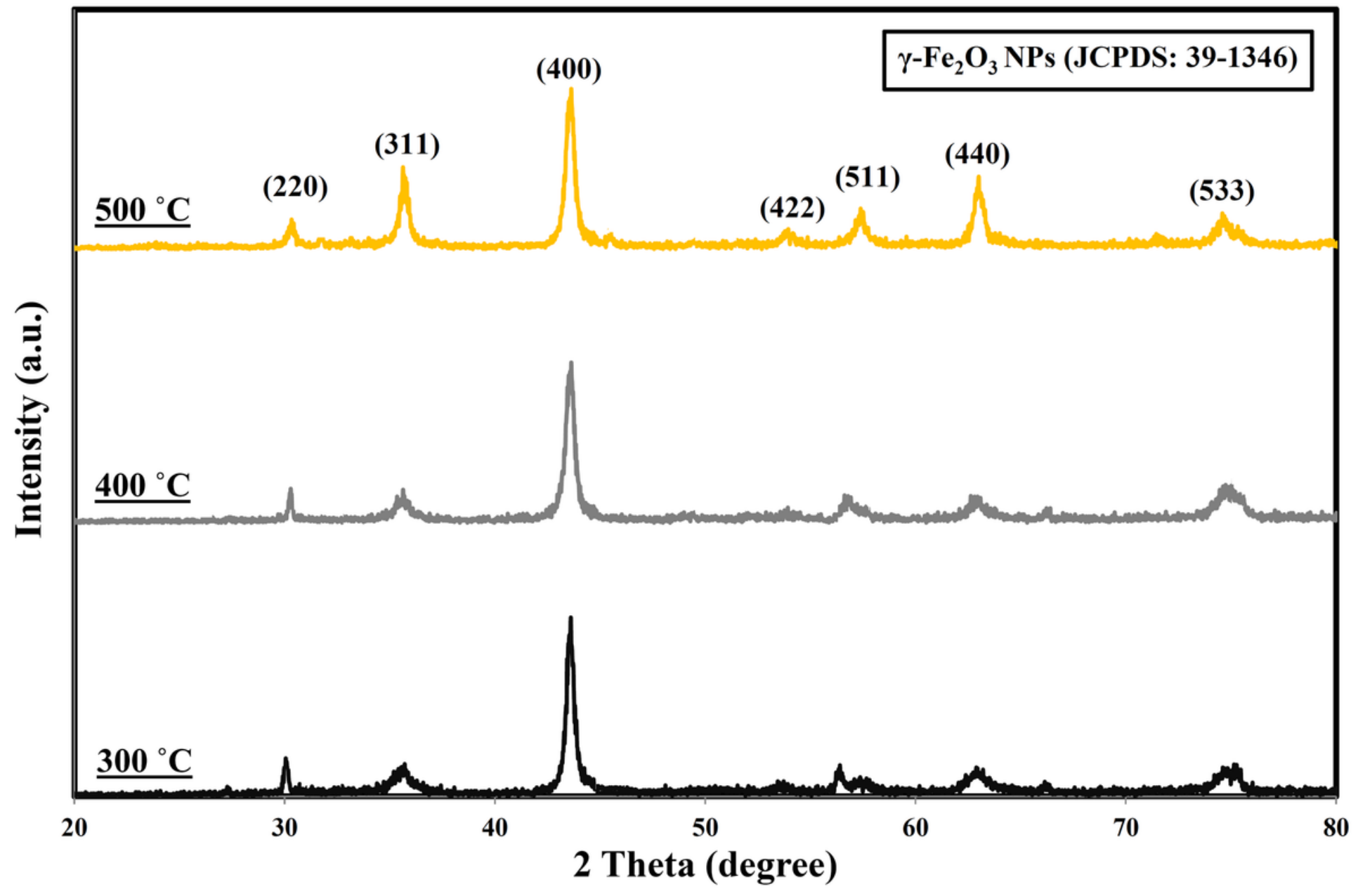

Figure 2

PXRD spectra of the synthesized $y-F e 203$ NPs using aqueous extract of $Z$. jujuba at 300,400 and $500{ }^{\circ} \mathrm{C}$. 

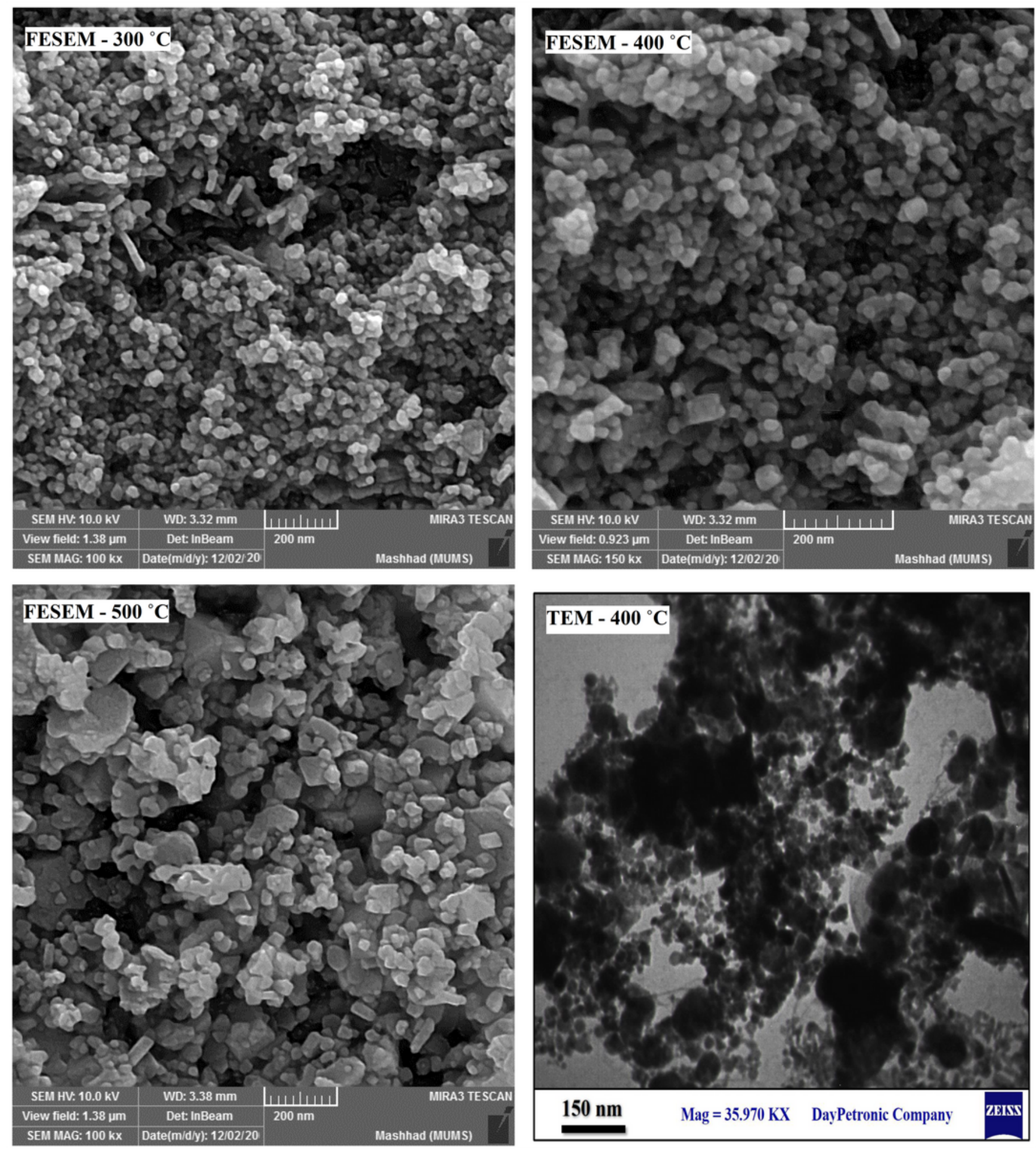

\section{Figure 3}

FESEM and TEM images of the synthesized $\mathrm{y}$-Fe203 NPs using aqueous extract of $Z$. jujuba at 300, 400, and $500{ }^{\circ} \mathrm{C}$. 


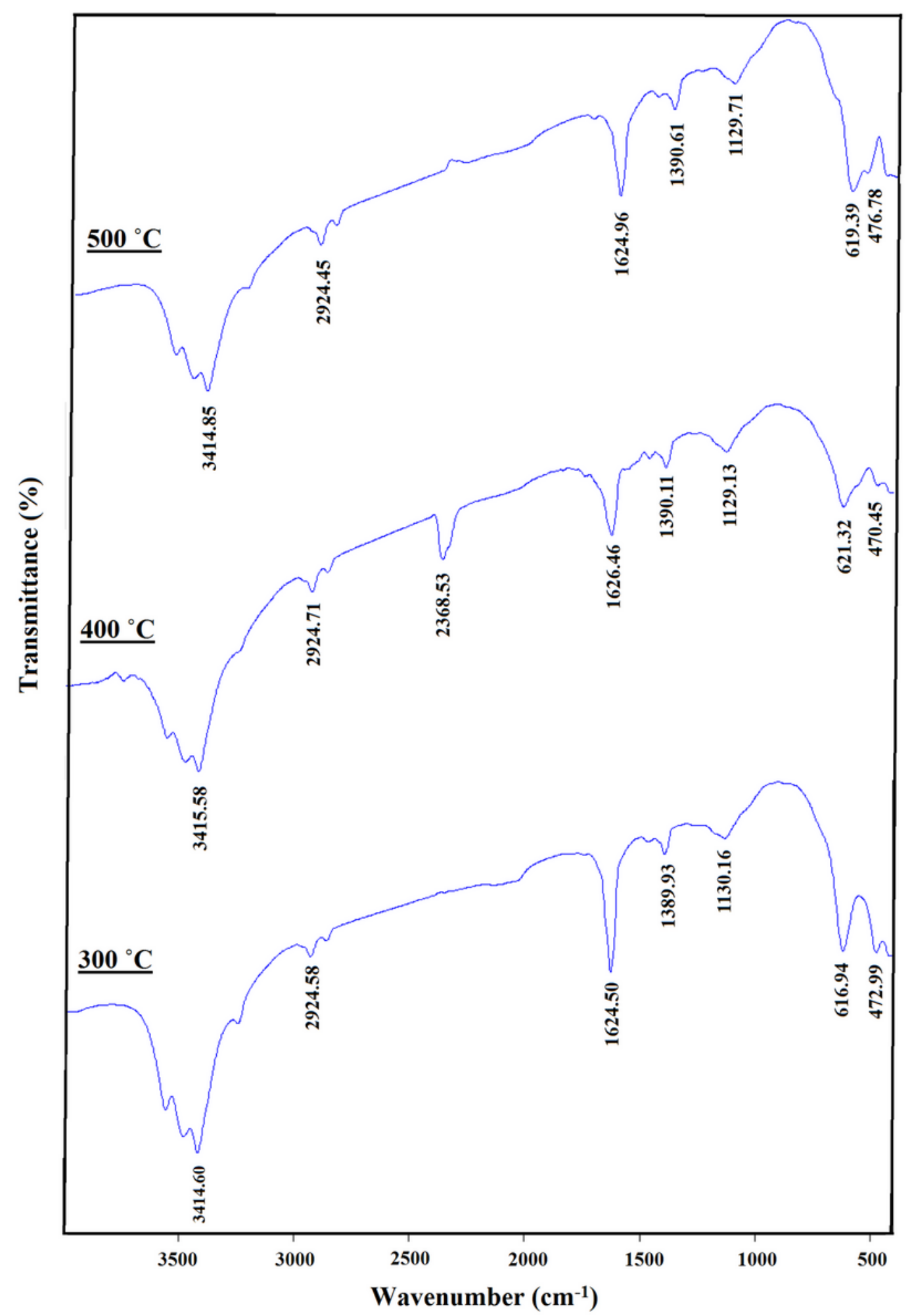

Figure 4

FT-IR spectra of the synthesized $y-F e 203$ NPs using aqueous extract of Z. jujuba at 300,400 , and $500{ }^{\circ} \mathrm{C}$. 


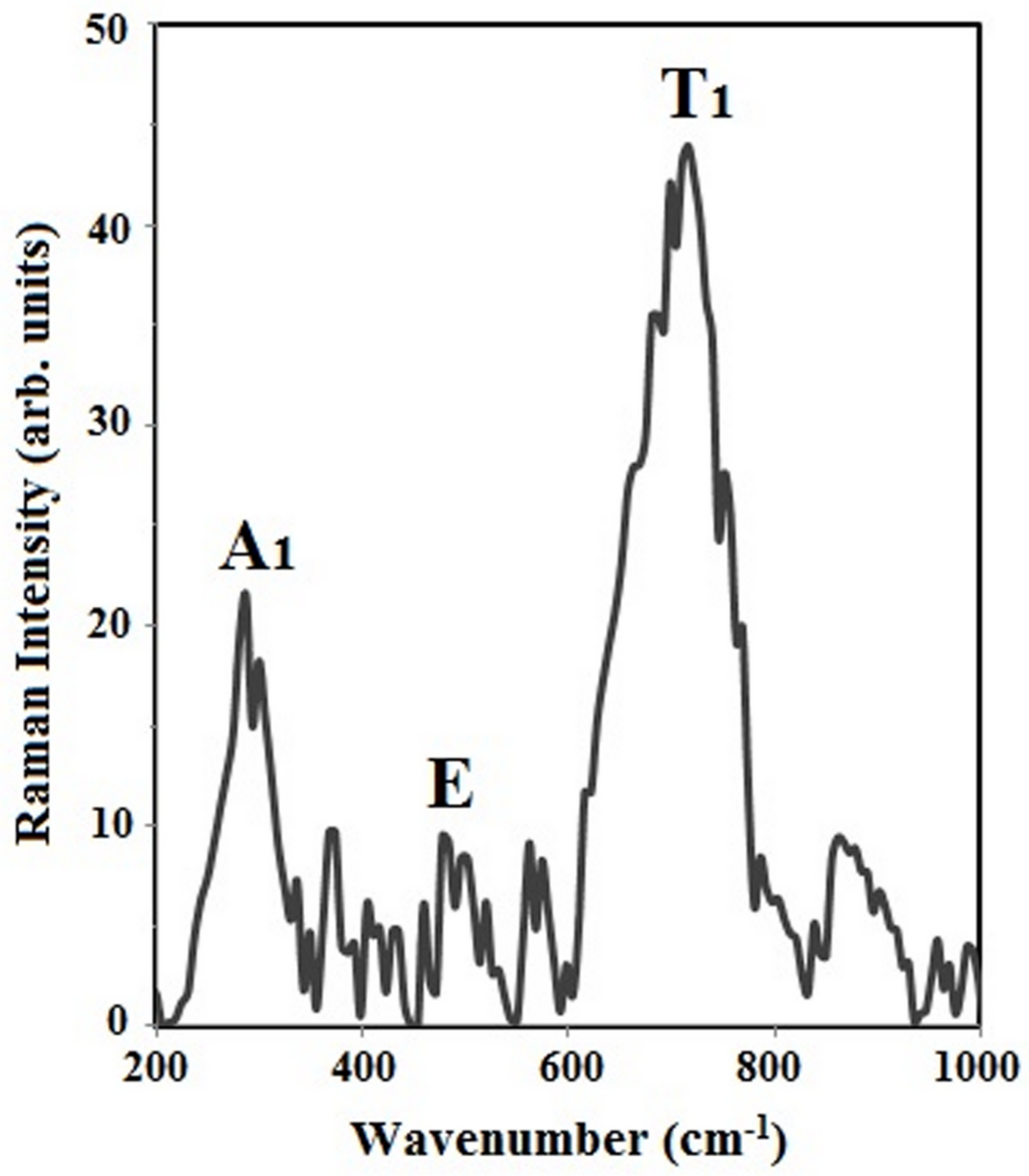

Figure 5

Raman spectrum of the synthesized $\mathrm{y}-\mathrm{Fe} 203 \mathrm{NPs}\left(\right.$ at $400^{\circ} \mathrm{C}$ ) using aqueous extract of $Z$. jujuba. 


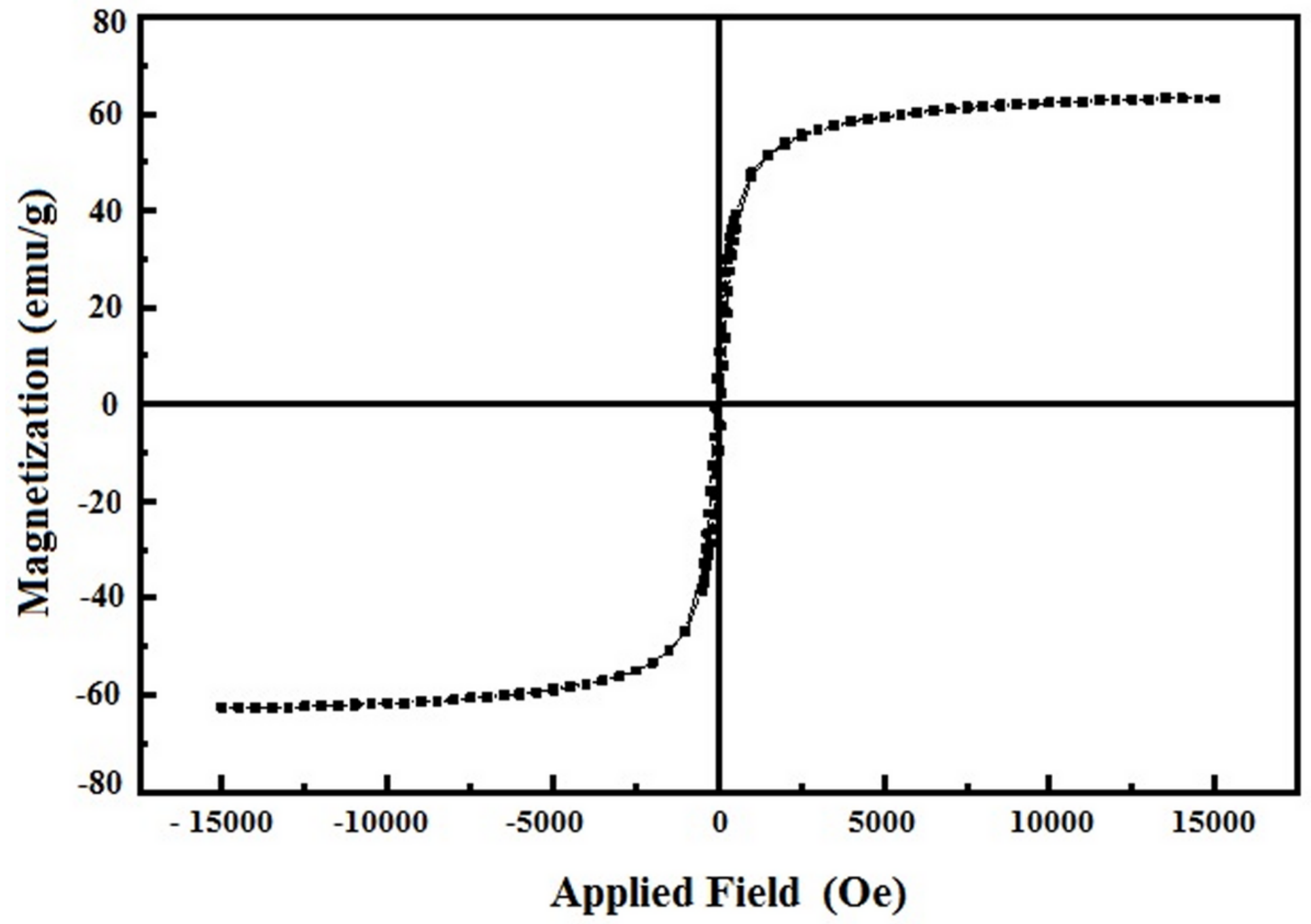

Figure 6

VSM graph of the synthesized $y-F e 203$ NPs using aqueous extract of Z. jujuba. 

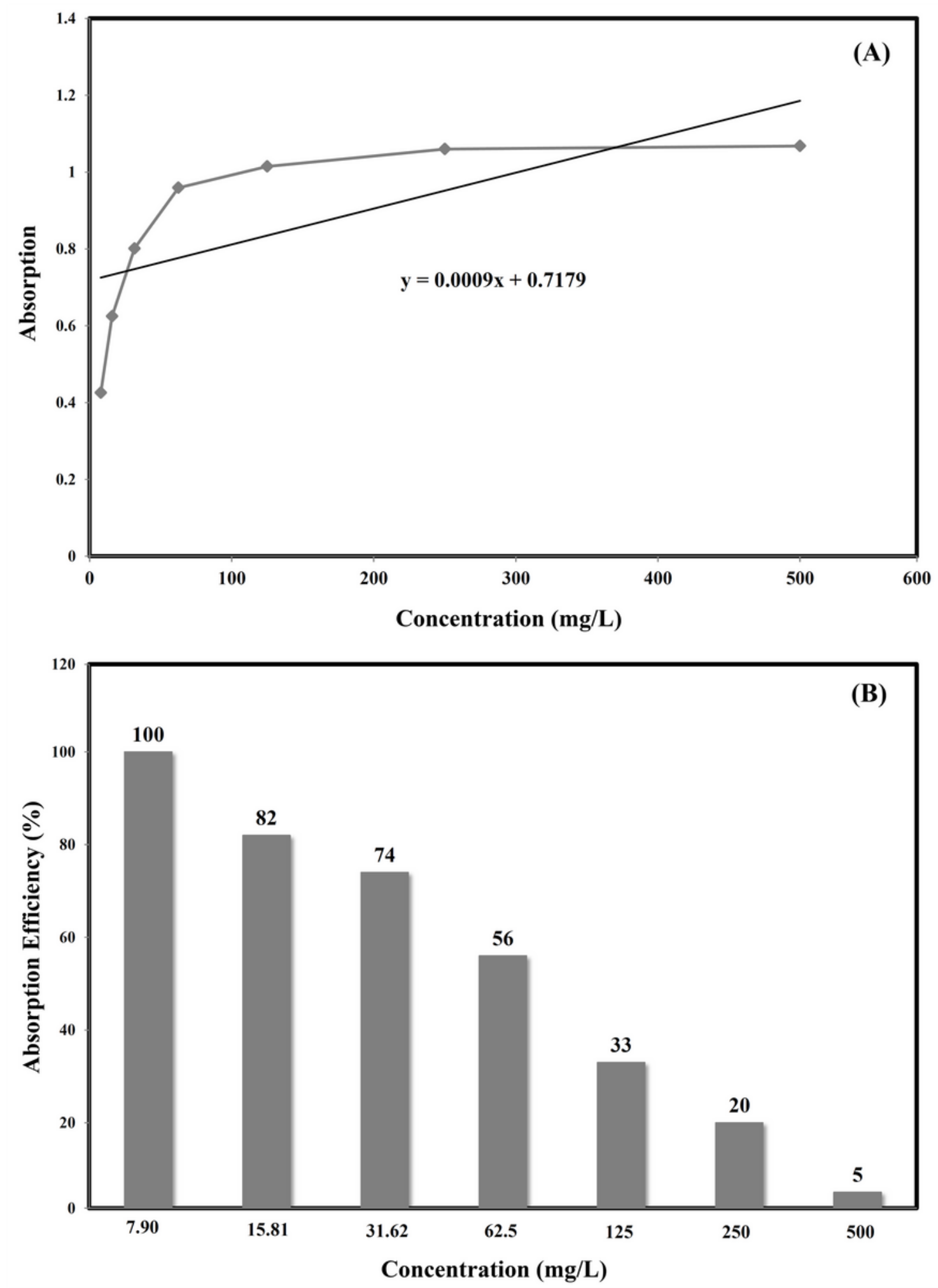

Figure 7

(A) Standard curve of lead absorption using synthesized $\mathrm{y}$-Fe203 NPs at $400{ }^{\circ} \mathrm{C}$, (B) Adsorption efficiency of nanoparticles in different concentrations of lead at the $\mathrm{pH}$ of 8. 

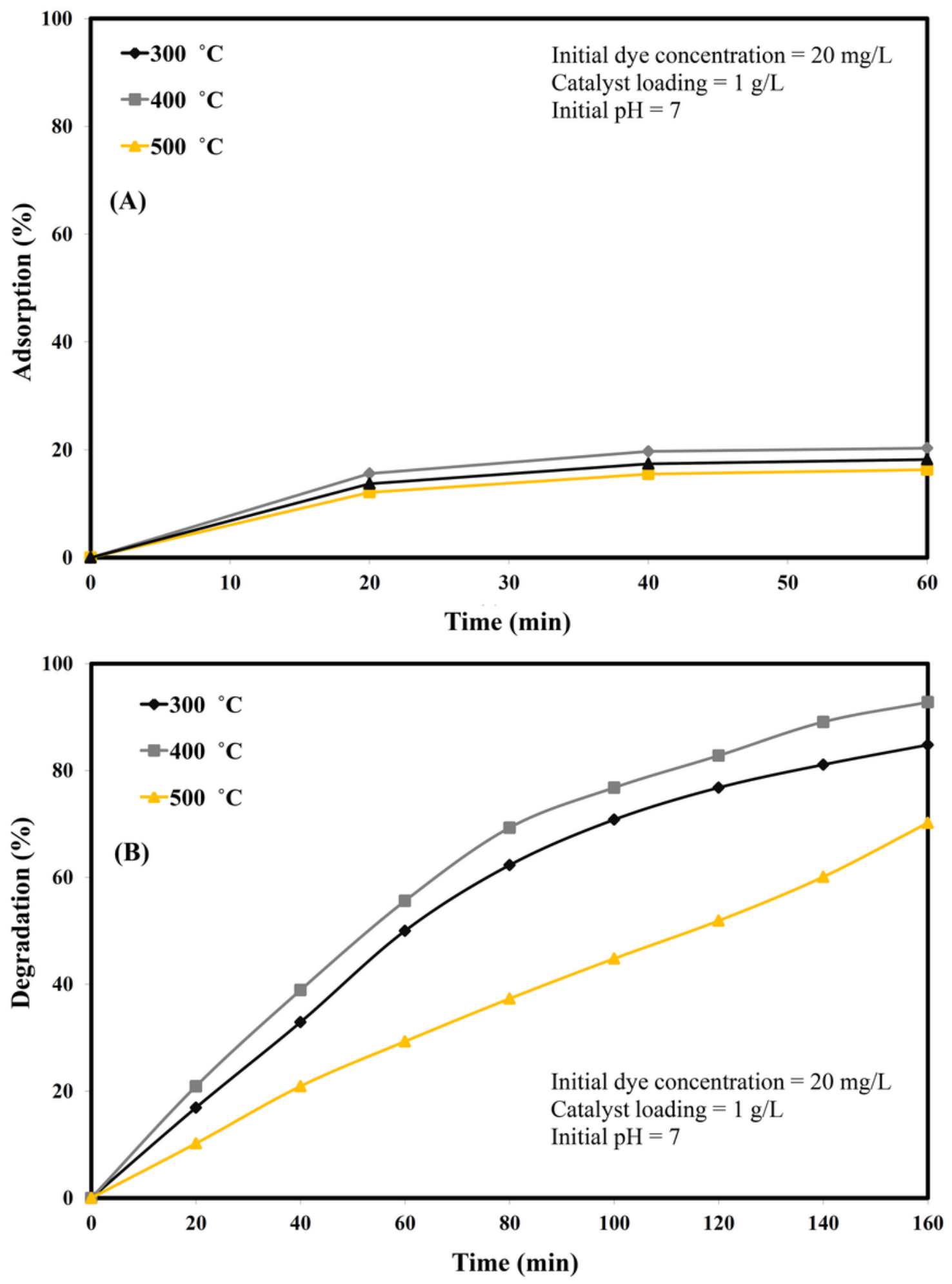

\section{Figure 8}

Photocatalytic degradation of MB using Y-Fe203 NPs under solar-light (A) adsorption and (B) degradation. 


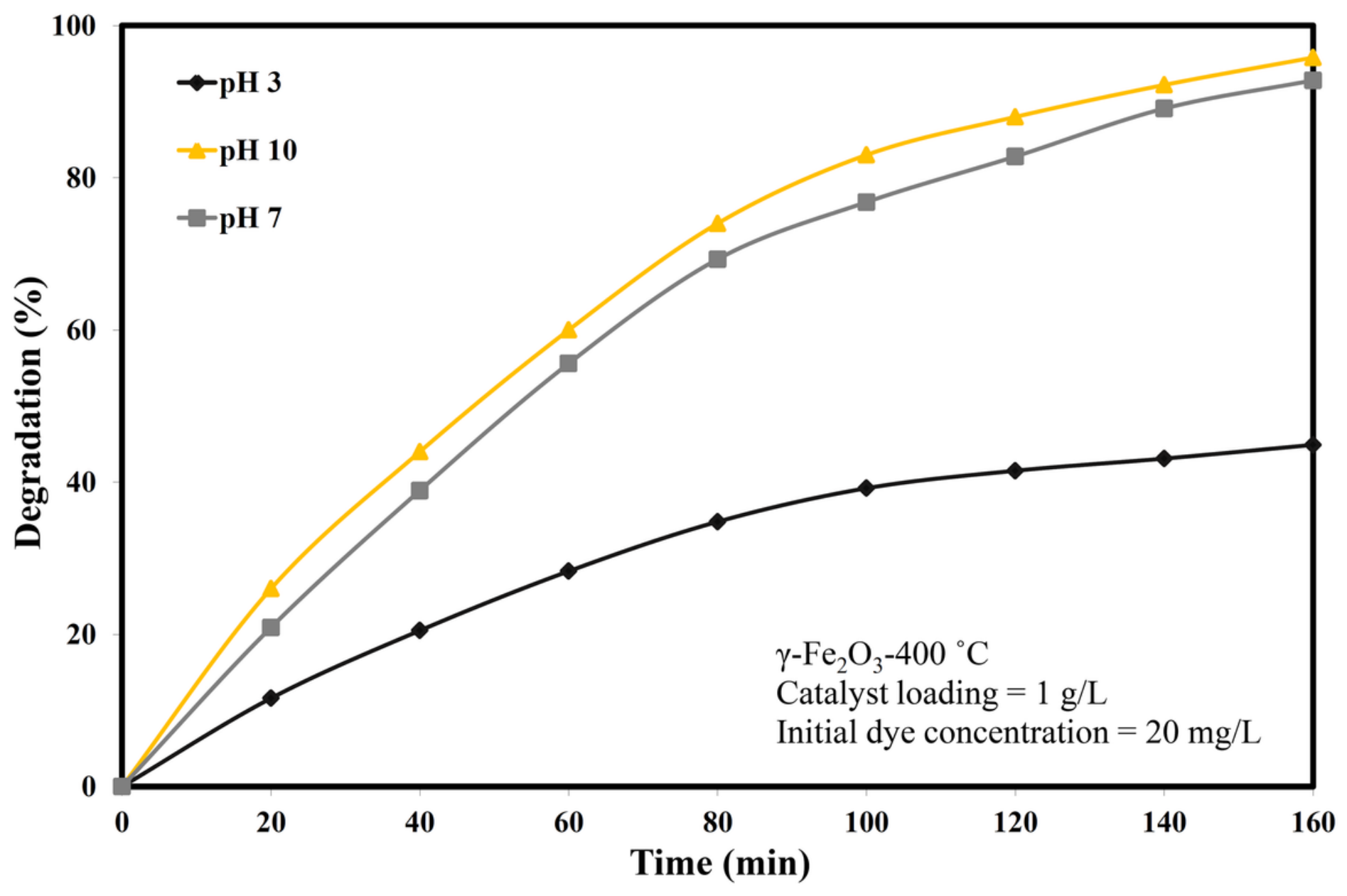

Figure 9

Influence of $\mathrm{pH}$ on photo-removal of methylene blue from wastewater using $\mathrm{y}-\mathrm{Fe} 2 \mathrm{O} 3 \mathrm{NPs}$ at $400{ }^{\circ} \mathrm{C}$. 


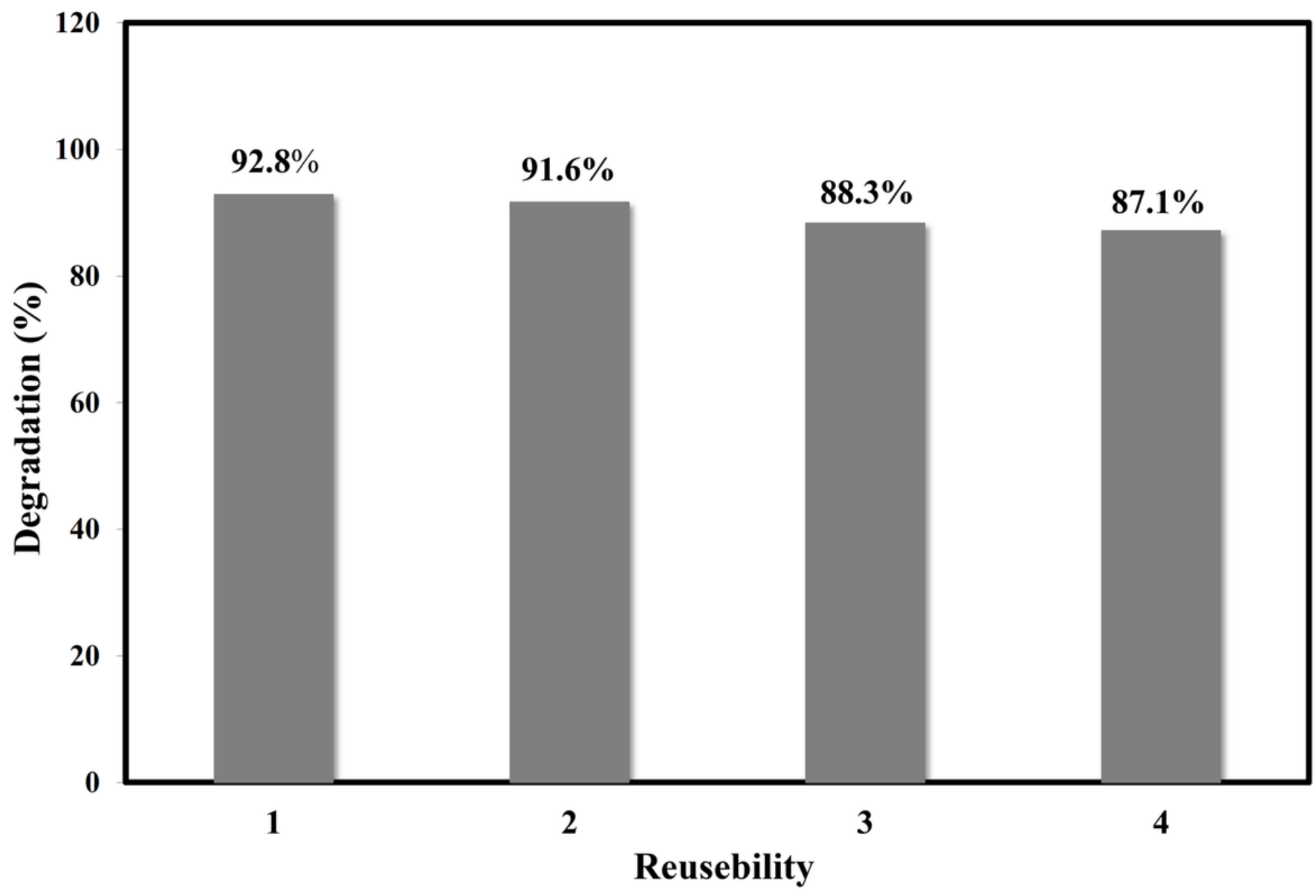

Figure 10

The reusability of synthesized $y-\mathrm{Fe} 2 \mathrm{O} 3 \mathrm{NPs}$ at $400{ }^{\circ} \mathrm{C}$ toward photo-degradation of methylene blue. 